\title{
Research on Influencing Factors of Soft Text Marketing Effect Based on ISM Model
}

\author{
Wang Yifeng ${ }^{1}$, Wang Yue ${ }^{2}$ \\ ${ }^{1}$ Xidian University, School of Economics and Management, \\ No.2 South Tai Bai Road, Yanta District, Xi'an 710071, Shaanxi Province, China \\ ${ }^{2}$ Xidian University, School of Economics and Management \\ No.266 Xinglong Xi Feng Road, Changan District, Xi'an 710126, Shaanxi Province, China
}

\begin{abstract}
The analysis method of structure interpretation model and factor analysis method is used to analyze the factors affecting the marketing effect of soft text. The calculation results show that the influence degree of each factor on the soft language marketing effect is primary and secondary.
\end{abstract}

Keywords: ISM model; factor analysis; soft marketing; influential factors

\section{Introduction}

Soft text marketing theory is a new theory for "strong marketing", It emphasizes that enterprises must respect the feelings and experiences of the consumers while they are doing marketing activities, In a "pull" way, Let consumers voluntarily accept information from enterprises. In essence, soft text marketing is a business strategy that is soft and permeated by enterprises in the form of advertising. Usually, with the help of word expression and dissemination of public opinion, consumers can agree with certain concepts, viewpoints and analysis ideas, so as to achieve the purpose of brand publicity and product sales.

In its article, Dykeman explains social media to publish digital creative content, get real-time feedback through online discussions, reviews, and change and modify digital content. Ahmad Hafeez Anjum points out that the marketing of soft text is a kind of social marketing. Ye Jing based on the Lasswell 5W mode, compares the five aspects of micro-blog marketing and WeChat marketing main body, communication content, media platform, audience and communication effect.Yong $\mathrm{Xia}$ is exploring the participation of college students in WeChat's marketing activities. In a quantitative way, it is found that WeChat's popularity, interaction and opinion leaders have a significant impact on user attitudes and participation. Yu Jing is considering the influence of user information dissemination process of the non uniform distribution under the premise of quantitative study found no significant relationship between the number of overall user's influence and attention, but for influential authentication users, has significant positive correlation between the number of fans and its influence. BiLingyan micro-blog through the dissemination of information flow and PageRank algorithm combined with the proposed model, effect evaluation of enterprise micro-blog marketing, the empirical research shows that the more the number of forwarding post does not represent the marketing effect is better, relatively speaking, the influence of user interaction can improve the effect of forwarding micro-blog marketing enterprises.

From the above literature, we can see that the past scholars' research on soft language marketing is mostly based on the background of soft language marketing, the research of social media, or the specific way of soft language marketing, for example, the marketing of WeChat. But at present, the implementation of soft language marketing is not good. The factors that influence the marketing effect of soft ware are numerous, and they are interrelated with each other. When analyzing the influence factors, it is difficult to accurately quantify the interaction between various factors. At present, the analysis of the failure factors of the soft text marketing is mostly qualitative analysis, and the quantitative research is less. This paper uses the structural interpretation model and factor analysis method, these factors as a system, the relationship between numerous factors with hierarchical structure intuitively, to accurately analyze the relationship between various factors between, and according to the results of factor analysis to extract the influence factors of enterprise marketing effect, for the enterprise the marketing staff in the use of the marketing mode to provide practical significance.

\section{The Construction Principle of ISM}

The ISM (Interpretative Structural Modeling) is a system analysis method is widely used in system engineering, it through the structural model of complex system is analyzed, the factors of the system between the complex and messy relationship between structured and hierarchical processing, by clearly understanding the interaction relations between elements exist, so as to grasp the essence of the problem, and find solutions to the problems ${ }^{[1]}$.

The general process of implementing the ISM method is: (1) Make up the ISM team. The number of members of the group is generally about 10 people, and the members of the group are required to take a caring attitude towards the problems to be solved and understand the essence of the

\section{Volume 6 Issue 12, December 2017}




\section{International Journal of Science and Research (IJSR) \\ ISSN (Online): 2319-7064}

Index Copernicus Value (2016): 79.57 | Impact Factor (2015): 6.391

problem. Be able to ensure that people with different views enter the group, such as those who have the ability to make decisions in time to join the group. Information should be full and communication should be smooth. (2) Set the problem. In the preparatory phase of the ISM, there must be a consensus on the setting of the problem, and the provisions are made in the form of text. (3) Select the element items that constitute the problem. (4) It is clear that there is no relation between the factors and the construction of a directed graph. (5) Interpretation of the meaning of the structural model.

The basic purpose of factor analysis is to describe many indicators or factors linked by a few factors, is related closely to several variables in the same class, each class variable becomes a factor of several factors with less data reflect the original information most. Using this technology, we can easily find out the main factors that affect the effect of the soft text marketing, and the size of their influence.

The basic steps of implementing factor analysis method are: 1) Determine whether the variables to be analyzed are suitable for factor analysis. (2) Structural factor variables. 3 ) The rotation method is used to make the factor variable interpretable. (4) Calculate factor variable score.

This paper uses the interpretative structural model (ISM) interpretation of the relationship between the factors influencing the marketing effect of the enterprise soft, clear relationship between the primary and secondary factors; then using principal component factor extraction enterprise soft marketing effect analysis method, analysis of the factors affecting the forming of orderly structure.

\section{Determining the influence factors of the marketing effect of enterprise soft text}

Soft ware marketing means that consumers can enter into the "thinking circle" set by enterprises through specific concept demands and facts, reasoning and attack, and achieve a rapid and effective sale of text and oral communication with a strong targeted psychological attack. For example: news, third party comments, interviews, interviews, word of mouth, and so on. Duer and others think that soft ware marketing is a network marketing way that enterprises use the Internet technology to integrate the resources of many domestic websites, and disseminated the related information in a soft way in a timely, comprehensive, effective and economic way to the public.

Yang Feixue believes that the influencing factors of WeChat e-commerce marketing in small and medium-sized cities are residents' consumption level, customers' distribution characteristics, consumption patterns, consumers' understanding and trust of e-commerce marketing and so on. Zhang Yan and others believe that the influencing factors of WeChat's friend circle marketing are the identity of the original publisher, the identity of forwarder, the content of marketing information, the time and frequency of marketing information push, and the precise customer group.Lu
Zhoudan argues that the influence factors of online word-of-mouth information receiver, including the initiative, professional attitude, etc.; the sender of information, including professional attitude, communication and influence, motivation factors; network structure factors, including the type of site, the user personalized web page settings, network relationship strength; reputation information factors, including pictures, mood the shape, etc. Liu Tong et al. Factors that influence the film with micro-blog marketing and environment and can not and the environment, and the environment including script storytelling skills and level, and the people living close to the script; and not including the environmental agenda setting of the media environment influence, with micro-blog propaganda and real life.

The effect of enterprise soft text marketing depends on the joint action of the internal and external environment of the enterprise. According to previous research, the marketing effect of enterprise soft text mainly depends on three aspects: the subject of the audience, the means of marketing and the level of marketing.In this paper, through the analysis of the related literature of enterprise soft text marketing, the factors that affect the marketing effect of corporate soft text are summarized :1)Demographic factors: age, sex, education and social relations; (2) The internal environment factors of an enterprise include: technology level, prestige, influence, marketing mode, corporate culture, interaction with customers, product characteristics, corporate image, organizational structure, staff quality, social status and customer satisfaction. (3) External environment: the overall technical level of the society, the mainstream social software, the smooth communication of information, the quality of the group culture and the social and economic situation.

The purpose of this study is to find out the relationship between the factors that affect the marketing effect of the company's soft text. Therefore, it is necessary to modify the factors affecting the marketing effect of the collected soft text. In this paper, the availability and rationality of the index are considered in the process of index selection. Among the factors of demographic statistics, two factors, such as education and social relations, are selected, but age and sex are not considered. In terms of internal environment factors, factors such as technology level, influence, product characteristics and staff quality are selected. Other factors are basically included in these 5 factors. And the marketing mode of the enterprise will change with the change of time. It is not convenient for us to consider at a time point, so it will not be considered. The social status and customer satisfaction of the enterprise are all qualitative factors, and it is difficult to quantify the analysis. At the same time, the factors of organization and management are added, and the factors of the overall level are divided into two factors: enterprise culture and management system and organizational support. External factors include the mainstream social software, information communication smoothness, social and economic situation and technology level and other macro factors, which are finally eliminated 


\section{International Journal of Science and Research (IJSR) \\ ISSN (Online): 2319-7064}

Index Copernicus Value (2016): 79.57 | Impact Factor (2015): 6.391

in the first two factors. Finally, we get 10 factors. As shown in Table 1.

Table 1: Influence factors of enterprise soft text marketing effect (S0)

\begin{tabular}{|c|c|c|}
\hline Number & Symbol & Factor \\
\hline 1 & $\mathrm{~S}_{1}$ & Enterprise culture and management system \\
2 & $\mathrm{~S}_{2}$ & Organizational support \\
3 & $\mathrm{~S}_{3}$ & Information communication unimpeded \\
4 & $\mathrm{~S}_{4}$ & Technical level of enterprises \\
5 & $\mathrm{~S}_{5}$ & Enterprise influence \\
6 & $\mathrm{~S}_{6}$ & Product spread surface \\
7 & $\mathrm{~S}_{7}$ & Mainstream social software \\
8 & $\mathrm{~S}_{8}$ & Staff quality \\
9 & $\mathrm{~S}_{9}$ & Educational level \\
10 & $\mathrm{~S}_{10}$ & Social relations of the audience \\
\hline
\end{tabular}

\section{ISM analysis of the influence factors of corporate soft text marketing effect}

This research adopts the expert investigation method, through a questionnaire survey of experts in the field of marketing and research, 25 questionnaires, 25 valid questionnaires, to determine the relationships between the factors influencing factors from enterprise soft effect, and then summarized the results obtained from the mutual relations of these factors.

1) A adjacency matrix is established according to the table of relevant elements

According to the relationship between factors, we establish adjacency matrix $\mathrm{A}$, and get the matrix A, where "1" indicates that $\mathrm{Si}$ has influence on $\mathrm{Sj}$, and "0" indicates that factor $\mathrm{Si}$ has no effect on $\mathrm{Sj}$. The adjacency matrix is shown as shown in Table 2.

Table 2: Adjacency Matrix

\begin{tabular}{|c|c|c|c|c|c|c|c|c|c|c|c|}
\hline & $\mathrm{S}_{0}$ & $\mathrm{~S}_{1}$ & $\mathrm{~S}_{2}$ & $\mathrm{~S}_{3}$ & $\mathrm{~S}_{4}$ & $\mathrm{~S}_{5}$ & $\mathrm{~S}_{6}$ & $\mathrm{~S}_{7}$ & $\mathrm{~S}_{8}$ & $\mathrm{~S}_{9}$ & $\mathrm{~S}_{10}$ \\
\hline $\mathrm{S}_{0}$ & 0 & 0 & 0 & 0 & 0 & 0 & 0 & 0 & 0 & 0 & 0 \\
\hline $\mathrm{S}_{1}$ & 1 & 0 & 0 & 1 & 1 & 0 & 0 & 1 & 0 & 1 & 1 \\
\hline $\mathrm{S}_{2}$ & 1 & 0 & 0 & 0 & 0 & 0 & 0 & 0 & 0 & 0 & 0 \\
\hline $\mathrm{S}_{3}$ & 1 & 0 & 0 & 0 & 0 & 1 & 0 & 0 & 0 & 1 & 1 \\
\hline $\mathrm{S}_{4}$ & 1 & 0 & 0 & 0 & 0 & 0 & 0 & 0 & 0 & 0 & 0 \\
\hline $\mathrm{S}_{5}$ & 1 & 0 & 0 & 0 & 0 & 0 & 0 & 0 & 0 & 0 & 0 \\
\hline $\mathrm{S}_{6}$ & 1 & 0 & 0 & 0 & 0 & 0 & 0 & 0 & 0 & 0 & 0 \\
\hline $\mathrm{S}_{7}$ & 1 & 1 & 0 & 0 & 1 & 0 & 0 & 0 & 1 & 0 & 1 \\
\hline $\mathrm{S}_{8}$ & 1 & 0 & 0 & 0 & 0 & 0 & 0 & 0 & 0 & 0 & 0 \\
\hline $\mathrm{S}_{9}$ & 1 & 0 & 0 & 0 & 0 & 0 & 0 & 0 & 0 & 0 & 0 \\
\hline $\mathrm{S}_{10}$ & 0 & 0 & 0 & 0 & 0 & 0 & 0 & 0 & 0 & 1 & 0 \\
\hline
\end{tabular}

2) Establishing the reachable matrix

According to the adjacency matrix of Table 1, the reachable matrix is established by the method of analysis. According to the formula $\mathrm{M}=(\mathrm{A}+\mathrm{I})^{\mathrm{r}-1} 1=(\mathrm{A}+\mathrm{I})^{\mathrm{r}}$, so $\mathrm{M}=(\mathrm{A}+\mathrm{I})^{3} \neq(\mathrm{A}+\mathrm{I})^{4}=(\mathrm{A}+\mathrm{I})^{5}$. The "I" is a unit matrix, and the results are shown in Table 3.
Table 3: reachable matrix

\begin{tabular}{|c|c|c|c|c|c|c|c|c|c|c|c|}
\hline & $\mathrm{S}_{0}$ & $\mathrm{~S}_{1}$ & $\mathrm{~S}_{2}$ & $\mathrm{~S}_{3}$ & $\mathrm{~S}_{4}$ & $\mathrm{~S}_{5}$ & $\mathrm{~S}_{6}$ & $\mathrm{~S}_{7}$ & $\mathrm{~S}_{8}$ & $\mathrm{~S}_{9}$ & $\mathrm{~S}_{10}$ \\
\hline $\mathrm{S}_{0}$ & 0 & 0 & 0 & 0 & 0 & 0 & 0 & 0 & 0 & 0 & 0 \\
\hline $\mathrm{S}_{1}$ & 1 & 1 & 0 & 1 & 1 & 1 & 0 & 1 & 1 & 1 & 1 \\
\hline $\mathrm{S}_{2}$ & 1 & 0 & 1 & 0 & 0 & 0 & 0 & 0 & 0 & 0 & 0 \\
\hline $\mathrm{S}_{3}$ & 1 & 0 & 0 & 1 & 0 & 1 & 0 & 0 & 0 & 1 & 1 \\
\hline $\mathrm{S}_{4}$ & 1 & 0 & 0 & 0 & 1 & 0 & 0 & 0 & 0 & 0 & 0 \\
\hline $\mathrm{S}_{5}$ & 1 & 0 & 0 & 0 & 0 & 1 & 0 & 0 & 0 & 0 & 0 \\
\hline $\mathrm{S}_{6}$ & 1 & 0 & 0 & 0 & 0 & 0 & 1 & 0 & 0 & 0 & 0 \\
\hline $\mathrm{S}_{7}$ & 1 & 1 & 0 & 1 & 1 & 1 & 0 & 1 & 1 & 1 & 1 \\
\hline $\mathrm{S}_{8}$ & 1 & 0 & 0 & 0 & 0 & 0 & 0 & 0 & 1 & 0 & 0 \\
\hline $\mathrm{S}_{9}$ & 1 & 0 & 0 & 0 & 0 & 0 & 0 & 0 & 0 & 1 & 0 \\
\hline $\mathrm{S}_{10}$ & 1 & 0 & 0 & 0 & 0 & 0 & 0 & 0 & 0 & 1 & 1 \\
\hline
\end{tabular}

3 ) The interlevel decomposition of the reachable matrix and the construction of an interpretative structure model. The solution of the ISM model is mainly divided into 3 steps: Regional decomposition, interstage decomposition and structure matrix establishment.

The relevant concepts:

Reachable set (R(ni)): By the set of elements corresponding to all the columns of the matrix element 1 in the line $\mathrm{R}(\mathrm{Ni})$ in the reachable matrix, that is, the set represented by $\mathrm{R}(\mathrm{Ni})$ is the upper set of the element.

Antecedent set (A(ni)) : By the set of elements corresponding to all the rows of the matrix element in the $\mathrm{Ni}$ column of the reachable matrix, the set of $\mathrm{A}(\mathrm{Ni})$ is the lower set of the element $\mathrm{Ni}$.

From the beginning of the reachability matrix, we listed in table 4 , first find the most advanced elements of its set, then they are from the matrix and then find out, thus most senior new elements in the matrix set, so we go step by step can be divided into different influence factors, the specific process is shown in the table below. Corresponding to all the columns of the matrix element 1 in the line $\mathrm{R}(\mathrm{Ni})$ in the reachable matrix, that is, the set represented by $\mathrm{R}(\mathrm{Ni})$ is the upper set of the element.

Table 4: inter level decomposition

\begin{tabular}{|c|c|c|c|}
\hline Elements & $\mathrm{R}(\mathrm{Si})$ & $\mathrm{A}(\mathrm{Si})$ & $\begin{array}{l}\mathrm{R}(\mathrm{Si}) \\
\cap \mathrm{A}(\mathrm{Si})\end{array}$ \\
\hline $\mathrm{S}_{0}$ & 0 & $\begin{array}{c}1,2,3,4,5,6, \\
7,8,9,10,\end{array}$ & 0 \\
\hline $\mathrm{S}_{1}$ & $\begin{array}{c}0,1,3,4,5,7, \\
8,9,10,\end{array}$ & 1,7 & 1,7 \\
\hline $\mathrm{S}_{2}$ & 0,2 & 2 & 2 \\
\hline $\mathrm{S}_{3}$ & $0,3,5,9,10$ & $1,3,7$ & 3 \\
\hline $\mathrm{S}_{4}$ & 0,4 & $1,4,7$ & 4 \\
\hline $\mathrm{S}_{5}$ & 0,5 & $1,3,5,7$ & 5 \\
\hline $\mathrm{S}_{6}$ & 0,6 & 6 & 6 \\
\hline $\mathrm{S}_{7}$ & $\begin{array}{c}0,1,3,4,5,7 \\
8,9,10\end{array}$ & 1,7 & 1,7 \\
\hline $\mathrm{S}_{8}$ & 0,8 & $1,7,8$ & 8 \\
\hline $\mathrm{S}_{9}$ & 0,9 & $1,3,7,9,10$ & 9 \\
\hline $\mathrm{S}_{10}$ & $0,9,10$ & $1,7,10$ & 10 \\
\hline
\end{tabular}

\section{Volume 6 Issue 12, December 2017}




\section{International Journal of Science and Research (IJSR) \\ ISSN (Online): 2319-7064}

Index Copernicus Value (2016): 79.57 | Impact Factor (2015): 6.391

Because the level is only $\mathrm{R}(\mathrm{S} 0)=\mathrm{R}(\mathrm{S} 0) \mathrm{n}$ A (S0), the highest level elements is S0, then the first layer element is $\{\mathrm{S} 0\}$, corresponding to their S0 rows and columns are reachable matrix second, then find the most advanced new factors in the rest of the reachability matrix. By analogy.
Therefore, on the same principle, we can get second levels of elements set as $\{\mathrm{S} 2, \mathrm{~S} 4, \mathrm{~S} 5, \mathrm{~S} 6, \mathrm{~S} 8, \mathrm{~S} 9\}$; third level set of elements $\{\mathrm{S} 3, \mathrm{~S} 10\}$; the most basic one is $\{\mathrm{S} 1, \mathrm{~S} 7\}$.

Now, we can draw a hierarchical structure model diagram, like Figure 1, based on the above analysis.

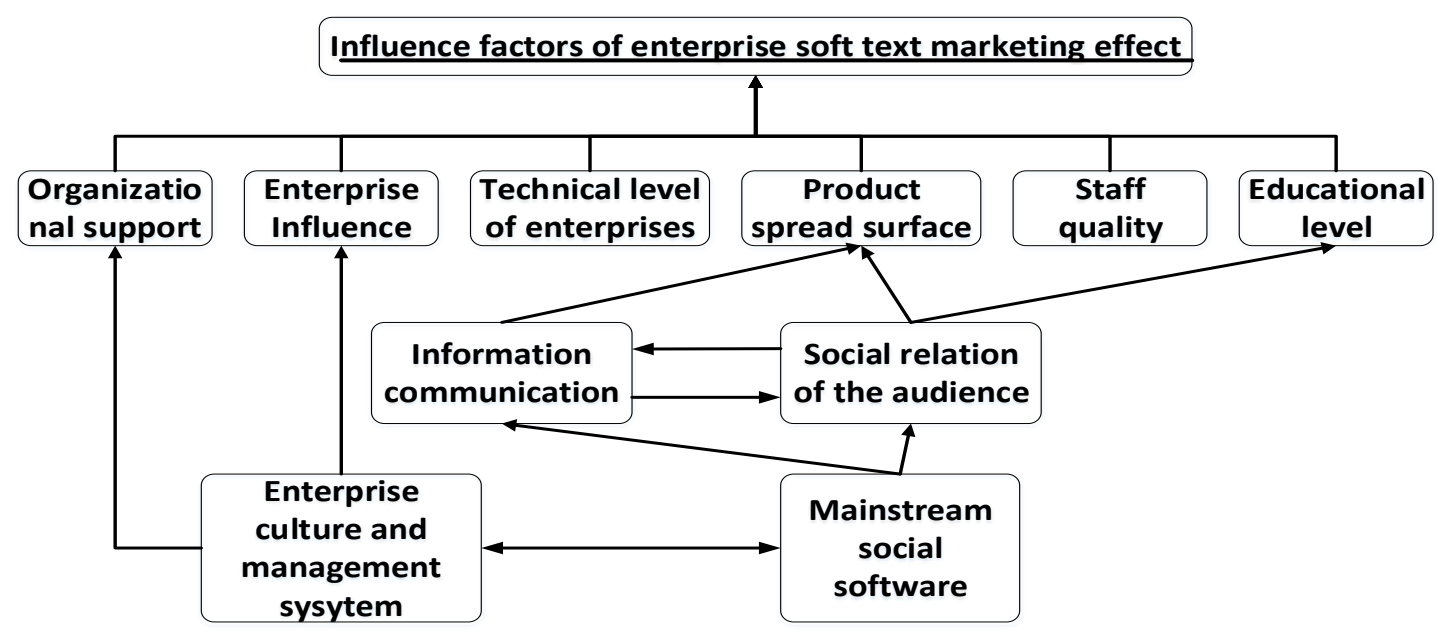

Figure 1: Hierarchical structure model

\section{4) Model Analysis}

From the structure diagram, it can be seen that the influence factor of the enterprise soft text marketing effect is a multi-level hierarchical system. The first level factors that directly influence the marketing effect of soft ware include organizational support, enterprise influence, enterprise technology level, product communication aspect, staff quality and education level. The second level factors include the smoothness of information dissemination and the social relations of the audience. On the one hand, the social relations of the audience affect the surface of the product. On the other hand, the wider the social relations, the more complex, the higher the degree of education. The smooth degree of information dissemination is the key to the smooth realization of the transfer of the product from the producer to the consumer. The lowest level of interpretation of structural models is two factors, namely, corporate culture and management systems, and mainstream social software. Enterprise culture and management system directly affect the organization's support for marketing business, and the influence of enterprises depends on the advanced nature and rationality of the system and culture. The mainstream of social software on the dissemination of information flow of play a decisive role, and the widespread use of social software also expanded the audience of social networks, enterprises only make good use of the mainstream of social software, to update their information reserves, and constantly improve the cultural and organizational structure.

\section{Factor analysis on Influence Factors of enterprise soft text marketing effect}

1) Using expert survey method, the importance of each variable is assigned to 1-10 points. Through expert scoring, 25 individuals' scores of 10 factors are taken as raw data, and analyzed by SPSS software.

Table 5: Influence factors of enterprise soft text marketing effect

\begin{tabular}{|c|c|}
\hline Number & Factor \\
\hline 1 & Mainstream social software \\
2 & Social relations of the audience \\
3 & Information communication unimpeded \\
4 & Product spread surface \\
5 & Enterprise influence \\
6 & Technical level of enterprises \\
7 & Enterprise culture and management system \\
8 & Staff quality \\
9 & Educational level \\
10 & Organizational support \\
\hline
\end{tabular}

First, it is necessary to test whether the data conforms to the test conditions of factor analysis, and the above variables are measured by KMO sample measurement and Bartlett spherical test. Test results show: The KMO sample measurement value is 0.748 , which is significantly greater than the specified measurement value 0.7 , while the Bartlett spherical test corresponds to the significant level Sig. value is 0 , far less than the prescribed value 0.001 . Therefore, the above variables are in accordance with the test conditions of factor analysis, and the result of factor analysis is shown by the factor interpretation of the total variance detail table. 


\section{International Journal of Science and Research (IJSR) \\ ISSN (Online): 2319-7064}

Index Copernicus Value (2016): 79.57 | Impact Factor (2015): 6.391

Table 6: Factor explanatory total variance detail table

\begin{tabular}{|c|c|c|c|c|c|c|c|c|c|}
\hline \multirow{2}{*}{ Component } & \multicolumn{3}{|c|}{ Initial Eigenvalues } & \multicolumn{3}{|c|}{ Extraction Sums of Squared Loadings } & \multicolumn{3}{|c|}{ Rotation Sums of Squared Loadings } \\
\hline & total & variance $\%$ & Accumulation \% & total & variance $\%$ & Accumalation $\%$ & total & variance $\%$ & Accumulation \% \\
\hline 1 & 6.605 & 33.024 & 33.024 & 6.605 & 33.024 & 33.024 & 4.917 & 24.584 & 24.584 \\
\hline 2 & 4.524 & 22.621 & 55.645 & 4.524 & 22.621 & 55.645 & 4.287 & 21.435 & 46.019 \\
\hline 3 & 2.890 & 14.450 & 70.095 & 2.890 & 14.450 & 70.095 & 4.015 & 16.076 & 62.095 \\
\hline 4 & 2.574 & 12.870 & 82.965 & 2.574 & 12.870 & 82.965 & 3.374 & 12.660 & 74.755 \\
\hline 5 & 1.678 & 8.394 & 91.359 & 1.679 & 8.394 & 91.359 & 3.145 & 8.210 & 82.965 \\
\hline 6 & .886 & 3.425 & 97.784 & & & & & & \\
\hline 7 & .443 & 2.216 & 100.000 & & & & & & \\
\hline 8 & $4.065 \mathrm{E}-16$ & $2.003 \mathrm{E}-15$ & 100.000 & & & & & & \\
\hline 9 & $2.686 \mathrm{E}-16$ & $1.343 \mathrm{E}-15$ & 100.000 & & & & & & \\
\hline 10 & $1.834 \mathrm{E}-16$ & $9.170-16$ & 100.000 & & & & & & \\
\hline
\end{tabular}

The above table shows that the eigenvalues of the first 5 main components are greater than 1 , while the sum of the 5 eigenvalues account for $82.964 \%$ of the total eigenvalues, which means that the five components can be used to interpret the data, covering data $82 \%$, and the degree of deletion is relatively small. By using the maximum variance orthogonal rotation method that can reasonably explain potential factors, we analyze the rotated factor load matrix, and see the factor load matrix table in detail.

Table 7: Factor load matrix table

\begin{tabular}{ccccc}
\hline 1 & 2 & 3 & 4 & 5 \\
\hline .348 & -.099 & -.840 & .204 & .098 \\
-.385 & .292 & -.752 & .147 & .246 \\
.468 & -.814 & -.678 & .092 & .125 \\
.052 & .769 & .641 & .327 & -.233 \\
.146 & -.737 & .545 & .243 & .021 \\
.755 & .187 & .183 & -.247 & .379 \\
.619 & .235 & .399 & .080 & .257 \\
-.615 & -.544 & -.027 & .128 & -.277 \\
.456 & .399 & .421 & .333 & .261 \\
.048 & -.410 & .095 & -.245 & .695 \\
\hline
\end{tabular}

From the table, the data can be obtained, the first principal component of a larger correlation coefficient on the technical level of enterprises, corporate culture and management system, staff quality and other three indicators, we named it the factors of enterprise development level; principal component and information transmission speed, transmission side, second products enterprises influence three indexes have great correlation coefficient, We name it as a information range factor; The third principal component has a larger correlation coefficient with the two indicators such as the mainstream social software and the social relationship of the audience. We name it as the main structure factor. There is a greater correlation between the fourth principal components and the educational level. We name it as an educational factor. There is a large correlation coefficient between fifth principal components and organizational support. We name it as an organization factor. Among them, the partition coefficient table of the principal component factor is detailed in the table of the principal component factor score matrix.
Table 8: Principal component factor score matrix table

\begin{tabular}{ccccc}
\hline 1 & 2 & 3 & 4 & 5 \\
\hline .167 & -.056 & -.088 & .084 & -0.057 \\
-.072 & .025 & -.024 & .243 & -.033 \\
.167 & -.018 & -.228 & .044 & .007 \\
-.018 & .193 & .003 & .036 & .164 \\
-.028 & -.084 & .235 & .090 & -.135 \\
.187 & .037 & -.028 & -.081 & .035 \\
.140 & .018 & .044 & .019 & .063 \\
-.213 & -.021 & .075 & .038 & .216 \\
.060 & .105 & .059 & .065 & -0.048 \\
-.003 & -.007 & .034 & -.279 & -.009 \\
\hline
\end{tabular}

The combination factor explains the data of the total variance detail table and the principal component factor score matrix table, and constructs the model of the influence factors of the soft text marketing effect: $\mathrm{F}=0.24584 F_{1}+0.21435 F_{2}+0.16076 F_{3}+0.1266 F_{4}+0.0821 F_{5}(1)$

2) model analysis: The model analysis shows that the key factor that affects the effect of soft text marketing is the level of enterprise development, the proportion of which is $24.584 \%$. The second factor is the range of information factors, the proportion is $21.435 \%$, third factors from the main structure factors, the proportion is $16.076 \%$, fourth factors are the factors of education, the proportion is $12.87 \%$, fifth factors are the organizational factors, the proportion is $8.21 \%$.

\section{Conclusions and Suggestions}

With the increasingly fierce competition in the market, the demand for marketing methods is becoming higher and higher. The quality of marketing has become the key factor affecting the development level of the enterprise. The technology of modeling ISM system based on hierarchical construction of each factor structural model, clarify the relationship between the influence factors and marketing effect, and further use the method of factor analysis, principal component extraction in the influence factors, according to hierarchy and common factors and the mutual dependence of the corresponding measures for the implementation of marketing, targeted to help enterprises in the process of marketing, targeted marketing strategy.

The results show that the most basic factors of enterprise marketing is social software and enterprise culture and 


\section{International Journal of Science and Research (IJSR) \\ ISSN (Online): 2319-7064}

Index Copernicus Value (2016): 79.57 | Impact Factor (2015): 6.391

management system, and the influence of the most important components of the enterprise information development level, scope, main structure and other factors. Based on this, puts forward some relevant suggestions on the development of enterprise marketing.

\section{1) Widespread use of social software}

The main ways of contemporary social communication is no longer a face-to-face dialogue, but through various types of social software, such as WeChat, QQ, micro-blog and so on. Economic development makes people's life pressure, when people are more willing to spare for recreation in the mobile phone, but not in the busy work so social groups continue to go. The information source to push mobile phone software, enterprises should be aware of the fact, grasp the social era of information dissemination advantages, actively use social software, communication with consumers on social software, shortened the distance with consumers, to achieve online marketing.

\section{2) Realizing comprehensive development}

The effect factors of enterprise culture, management system, economic strength and technology level of enterprise marketing plays a decisive role. Enterprises need to establish their own unique cultural concept, passed to consumers in the process of marketing in the brand image of enterprises deeply. Enterprise management system is the basic factor of enterprise development level. Only enterprises with flexible management structure, to improve the ability to respond to the outside world, in an invincible position in the competition. The information age, technology development has brought the huge challenge for the enterprise, network marketing has revolutionized the way of corporate marketing, enterprises need to learn new technology, and the use of technology to improve themselves, and social development not only was to beat other enterprises.

\section{3 ) Expanding the scope of information dissemination}

The competition of modern enterprises is the competition of information, who grasp more comprehensive information to occupy a favorable position in the fierce competition in the market. On the one hand, enterprises need to grasp from the consumer and competitor information, according to changes in consumer demand and competition strategy change timely adjust its strategy, always maintain the development posture leading. On the other hand, companies need to expand their products and services to spread information, let more consumers understand the enterprise product characteristics, and to take the initiative to spread the way to expand the product audience.

\section{4) Effective use of social relations}

Society is composed of a network, each person has their own social circle, when a product is a person acceptable means is a social circle accepted, when two social relations intersect and accept the product of the wider enterprises to effectively utilize. Consumers' social relationships, enhance consumer satisfaction, active marketing, expand the enterprise target customer groups in the double base of enterprise resources and customer resources. Not only save marketing costs, but also to enable consumers to achieve the maximization of information transfer value, help enterprises and consumers win-win.

Article Marketing has greatly promoted the development of electronic commerce, electronic commerce is popular to the public life. With the implementation and improvement of technology upgrading, related system and norms, marketing will be more favorable protection. The development of network information age, intelligent mobile phone universal use, enterprise marketing will have development prospect infinite.

\section{References}

[1] DUuYi. Research on the marketing of Internet soft text in China [J]. Trade in China, 2010, (7): 23-23

[2] YangFeixue. Research on the influencing factors of WeChat e-commerce marketing in small and medium-sized cities [J]. Journal of Liaoning University of Technology, 2016, 18(2): 26-20

[3] Zhang Yan. The influencing factors and Strategies of WeChat's circle of friends [J]. Young journalists, 2015, (7): $15-16$

[4] LuZhoudan. Analysis on Influence Factors of internet word-of-mouth [J]. Economic Forum, 2013, (10): $152-153$

[5] Liu Tong. Analysis of influence factors of film micro-blog marketing [J]. The press, 2012, (23): 69-70

[6] JinZaiwen. Factor analysis: statistical methods and application problems [M]. Shang Hai:Shanghai people's Publishing House, 2012. 57-64

[7] Nie Lei. WeChat circle: virtual community from the perspective of social network[J]. Reporter, 2013, (5): $75-76$

[8] Yuan Yi. Analysis of the influence factors of social media marketing by structural equation model [J]. Library and information work, 2011, (18): 57-60

[9] Ji Xiang. Web2.0 e-commerce under the social network model [J]. Library and information knowledge, 2016, (7): $94-97$

[10] Antony, Mayfield. What is social media[M]. Washington: Advances in Web Mining and Web Usage Analysis lecture notes in computers science, 2012.

\section{Author Profile}

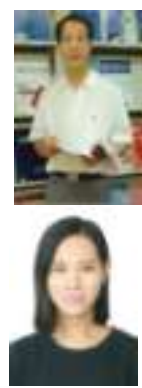

Wang Yifeng (1964--), male, Shanxi Xi'an, professor, School of Economics and Management, Xidian University. Research interests:Marketing management.

Wang Yue (1990--), female, Hebei Baoding, master, School of Economics and Management, Xidian University. Major:Business management. 